\section{Stenoses in Idiopathic Intracranial Hypertension: To Stent or Not To Stent?}

I read with great interest the paper entitled "Reversibility of Venous Sinus Obstruction in Idiopathic Intracranial Hypertension" recently published in the American Journal of Neuroradiology by Rohr et al. ${ }^{1}$ This paper presents the case histories of 3 patients with idiopathic intracranial hypertension (IIH) and venous outflow stenoses. The first patient had an initial resolution of her symptoms after insertion of a stent into the transverse sinus, but the symptoms recurred and a restenosis was noted just upstream from the stent. This patient was later treated with insertion of a shunt tube. In the second and third cases, the patients were treated with insertion of a shunt, with the venous stenoses in the second patient improving after the insertion. On the basis of these cases, the authors suggest that the elevated venous pressure in IIH is caused by the collapse of the sinuses. ${ }^{1}$ They go on to assert that insertion of a stent should be reserved for fixed stenoses and should not be used for dynamic stenoses. This suggestion is proposed because, logically, if the raised pressure in the CSF has caused the collapse of the venous sinus, then the elevated venous pressure cannot also be the cause of the raised CSF pressure. I wish to discuss whether the cause-and-effect relationship, as outlined, is the only one possible given the data as presented.

Most patients with IIH have morphologic stenoses in the venous outflow. $^{2}$ Many of these stenoses reduce the outflow by more than $70 \%$ in area and would be deemed significant if found on the arterial side of the vascular tree. Direct manometry has shown the pressure gradients across these stenoses to average $24 \mathrm{~mm} \mathrm{Hg},{ }^{3}$ which would also suggest that these stenoses were significant by the usual criteria. Finally, I have measured the arterial inflow and venous outflow in 21 patients with IIH and stenoses and found, on average, a 13\% reduction in the sagittal sinus outflow as a percentage of the inflow in IIH. ${ }^{4}$ This indicates that $140 \mathrm{~mL} / \mathrm{min}$ bypasses the dominant outflow stenosis via the collateral vessels, ${ }^{4}$ again suggesting significance.

Can we reconcile the apparent significant nature of the stenoses with the fact that they occur secondary to the CSF pressure? Intracranial pressure (ICP) is dependent on a balance between the production and reabsorption of CSF. Davson et $\mathrm{al}^{5}$ modeled the relationship between ICP and the formation and reabsorption of CSF showing that,

$$
\mathrm{ICP}=\mathrm{R}_{\text {out }} \times \mathrm{FR}_{\mathrm{CSF}}+\mathrm{P}_{\mathrm{SS}}
$$

where $\mathrm{R}_{\text {out }}$ is the resistance of CSF outflow, $\mathrm{FR}_{\mathrm{CSF}}$ is the formation rate of CSF, and $\mathrm{P}_{\mathrm{SS}}$ is the sagittal sinus pressure. In a report by King et $\mathrm{al}^{3}$ in which they studied 21 patients with IIH, a mean CSF pressure of $27 \mathrm{~mm} \mathrm{Hg}$ and sagittal sinus pressure of $22 \mathrm{~mm} \mathrm{Hg}$ gave a CSFsuperior sagittal sinus (SSS) gradient of $5 \mathrm{~mm} \mathrm{Hg}$, which is in the normal range $(2-6 \mathrm{~mm} \mathrm{Hg})$. Rearranging Davson's equation, we find that the CSF-SSS pressure gradient is equal to the product of the CSF rate of production and the resistance to flow across the arachnoid granulations, ie,

$$
\mathrm{ICP}-\mathrm{P}_{\mathrm{SS}}=\mathrm{R}_{\text {out }} \times \mathrm{FR}_{\mathrm{CSF}} .
$$

Malm et al ${ }^{6}$ used a technique of constant flow to measure $\mathrm{FR}_{\mathrm{CSF}}$ and showed it to be normal in this condition. If the gradient and the rate of formation are normal, then the $\mathrm{R}_{\text {out }}$ must also be normal in IIH. Therefore, the elevated venous pressure is the sole variable effecting the elevation in CSF pressure despite itself being secondary to the elevated CSF pressure. This finding indicates that a feedback loop must exist in which both the CSF and venous pressures are cause and effect. It follows that this condition could be treated by attacking either side of the feedback loop (ie, reducing the CSF pressure with placement of a shunt or stent into an overly compliant transverse sinus will break the loop). Thus, I believe that the assertion by Rohr et $\mathrm{al}^{1}$ that placement of a stent should not be offered to patients who have IIH and collapsible stenoses is not necessarily correct. The only proviso is that the stent must support all of the compliant sections of the venous system or the stenosis will recur (well documented by the authors in patient 1). Ultimately, whether the front-line treatment of $\mathrm{IIH}$ associated with collapsible venous outflow is stent placement or shunt insertion will depend on the relative morbidity of these procedures and their long-term rates of success.

\section{References}

1. Rohr A, Dörner L, Stingele R, et al. Reversibility of venous sinus obstruction in idiopathic intracranial hypertension. AJNR Am J Neuroradiol 2007;28:656-59

2. Higgins JN, Gillard JH, Owler BK, et al. MR venography in idiopathic intracranial hypertension: unappreciated and misunderstood. J Neurol Neurosurg Psychiatry 2004;72:621-25

3. King JO, Mitchell PJ, Thomson KR, et al. Manometry combined with cervical puncture in idiopathic intracranial hypertension. Neurology 2002;58:26-30

4. Bateman GA. Arterial inflow and venous outflow in idiopathic intracranial hypertension associated with venous outflow stenoses. J Clin Neurosci In press

5. Davson H, Welch K, Segal MB, eds. Physiology and pathophysiology of the cerebrospinal fluid. New York: Churchill Livingstone; 1987:485-21

6. Malm J, Kristensen B, Markgren P, et al. CSF hydrodynamics in idiopathic intracranial hypertension: A long-term study. Neurology 1992;42:851-58

Grant A. Bateman

Department of Medical Imaging John Hunter Hospital Newcastle, Australia

\section{DOI 10.3174/ajnr.A0804}

\section{Reply:}

Because venous sinus stenoses in idiopathic intracranial hypertension (IIH) can be reversed by lowering the intracranial pressure, I believe that these stenoses are caused primarily by elevated intracranial pressure. I think there might, furthermore, be a feedback mechanism in IIH such that an increase in intracranial pressure (due to impaired absorption of CSF?) leads to stenoses of the transverse sinuses and that these stenoses lead to an increase in intravenous pressure proximal to the stenoses (which can be measured directly by a catheter). This again could hamper absorption of CSF, leading to a further increase in pressure. (In theory, pressure would then rise infinitely, but in reality it does not. Therefore, the mechanisms must be somewhat more complex.) We saw cases of secondary intracranial hypertension demonstrating narrowing of large segments of the intracranial sinuses, whereas in IIH, there seems to be a predilection for the development of the stenoses in the lateral parts of the transverse sinuses. Therefore, patients with IIH probably have some pathoanatomic change in this region of the sinus ("vulnerable segments" may be secondary to hormonal changes).

I agree with Bateman that patients might profit from stent angioplasty, which interrupts the feedback mechanism. However, the problem is — as he stated and as our first patient demonstrated — that stent angioplasty might be necessary for all the "vulnerable" segments of the intracranial sinuses. Moreover, we probably tackle only a part of the problem with this procedure. On the other hand, there might be a subgroup of patients with IIH who have fixed sinus stenoses (eg, originating in venous sinus thrombosis) predisposing them for stent angioplasty. We have to prove though that these groups of patients really exist.

I also think there is a need for a randomized controlled multicenter trial in which the performance of stent angioplasty versus shunt surgery procedures is compared in patients with pharmacore- 